\title{
A post marketing evaluation of the efficacy of Rapid Recovery in reducing symptoms of hangover
}

\author{
Jan Beatrice Quinton ${ }^{*}$, Rhianna Megan Kemm² and Laurence Guy Howes ${ }^{3}$ \\ ${ }^{1}$ Phoenix Pharmaceuticals Australia Pty Ltd P.O. Box 820 Sanctuary Cove, Queensland, Australia \\ ${ }^{2}$ School of Allied Health Sciences, Griffith Health, Griffith University, Parkwood, Queensland, Australia \\ ${ }^{3}$ Professor of Pharmacology and Therapeutics, Griffith and Bond University Medical Schools, Gold Coast, Queensland Australia
}

\begin{abstract}
Rapid Recovery is a natural preparation of 1-cysteine with B and $\mathrm{C}$ group vitamins that has been designed to reduce symptoms of hangover and has been marketed in Australia and listed with the Therapeutic Goods Administration of Australia (TGA) as a natural product. Anecdotal reports suggest that it is effective. A post marketing evaluation of 19 subjects was performed where subjects who consumed on average about $100 \mathrm{~g}$ of alcohol in an evening received either Rapid Recovery or dextrose in a random order on 2 occasions at least 6 days apart. Symptoms of hangover were assessed the following morning.

General wellbeing improved (scale $1-10)$ from $3.47 \pm 1.18$ on dextrose to $8.00 \pm 0.84$ on Rapid Recovery $(\mathrm{P}<0.00001)$. Nausea, headache, and ability to concentrate improved by $260 \%(\mathrm{P}=0.0035), 222 \%(\mathrm{P}=0.0003)$, and $138 \%(\mathrm{P}<0.0001)$ respectively on Rapid Recovery. These results support the clinical impression that Rapid Recovery is an effective therapy for reducing at least some of the disabling symptoms of hangover.
\end{abstract}

\section{Introduction}

Alcohol induced hangover is responsible for a significant degree of morbidity in the community and is responsible for a high level of loss of productivity due to absenteeism from work and poor work performance [1]. In 2005 in Australia the loss of productivity due to hangover was A $\$ 1.2$ billion. By 2013 this had risen to A $\$ 6$ billion [1]. In the USA the corresponding figure for 2006 was approximately $\$ 179$ billion [2].

An effective treatment for the prevention of symptoms of hangover has not been found $[3,4]$. Rapid Recovery is a formulation comprised of readily available, non-toxic, unrestricted food products (vitamins and amino acids) that has been developed for the prevention of hangover symptoms based on the results of animal studies and the assumption that acetaldehyde accumulation plays a role in the production of hangover symptoms [5]. It has marketing approval as a listed natural therapy with the Therapeutic Goods Administration of Australia for the prevention of hangover. The clinical impression is that it is very effective. We performed a post marketing evaluation to test its efficacy in drinkers who regularly experience hangover symptoms. Hangover symptoms were defined as the unpleasant symptoms occurring the day after drinking alcohol at a time when plasma alcohol levels were not detectable.

\section{Methods}

The composition of Rapid Recovery consists of 1-cysteine, an amino acid that plays a crucial role in reversing oxidization in the liver partially due to conversion to glutathione. L-cysteine has been shown to enhance the breakdown and reduce the accumulation of acetaldehyde [6]. In addition, administration of l-cysteine to rats has been demonstrated to markedly reduce mortality due to acetaldehyde poisoning [7]. The dose chosen for l-cysteine was the relatively high dose recommended for use as an antioxidant [8]. Ascorbic acid was included as it is a potent antioxidant that contributes to the breakdown of acetaldehyde and has also been shown to reduce mortality due to acetaldehyde poisoning in rats $[9,10]$. The dose was chosen from studies in man of its antioxidant effect. Thiamine was included at a dose similar to that used to treat alcoholism as the addition of thiamine to l-cysteine enhanced the ability of l-cysteine to reduce mortality in rats poisoned with acetaldehyde [7]. Pyridoxine is included because of its' anti-nausea effect [11] and dextrose was included as a flavor additive. Dextrose has been demonstrated to correct some of the metabolic changes that accompany hangover but to have no effect on hangover symptoms [12].

The total weight of each dose of Rapid Recovery is $2 \mathrm{~g}$, administered as a powder dissolved in a flavored drink such as lemonade. One $2 \mathrm{~g}$ dose is taken at the end of the drinking session and a second $2 \mathrm{~g}$ dose is prepared and left at the bedside to be taken if the subject wakes through the night, or upon wakening in the morning. Rapid Recovery is a white powder and was prepared in clear sachets. Identical sachets of dextrose were used for comparison. Nineteen volunteers recruited by word of mouth who regularly experienced hangover symptoms (but were in good health) were evaluated. The subjects understood that they would be given Rapid Recovery on one occasion after an evening of drinking and dextrose on a separate occasion after drinking a similar amount of

Correspondence to: Jan Beatrice Quinton, Phoenix Pharmaceuticals Australia Pty Ltd P.O. Box 820 Sanctuary Cove, Queensland, Australia, Tel: +61 (0)7 3391 9777; Fax: +61 (0)7 3391 9799; E-mail: laurie.howes@health.qld.gov.au

Key words: alcohol, hangover prevention, rapid recovery

Received: February 15, 2018; Accepted: March 05, 2018; Published: March 08 2018 
alcohol over a similar time period. These two occasions were at least 6 days apart. Neither the subjects nor the study team were aware of the order that they received the two treatments until after the project had been completed. The treatments were prepared in sealed, numbered envelopes by an independent person according to a randomization code (in blocks of four) generated by the independent person.

The subjects consumed an amount of alcohol of their choice in the type of drink of their choice over four hours at a series of parties held at the sponsors' residence. A standardized meal was provided. The amount of alcohol each subject consumed was recorded and the subjects were instructed to consume the same amount on each occasion. The subjects slept over at the sponsors house and the next morning after they woke they were given a standard breakfast and blew into a Lion breathalyser to confirm that their blood alcohol levels were zero. They were then immediately asked to place marks on several $100 \mathrm{~mm}$ visual analogue scales to illustrate the severity of a selection of previously validated symptoms of hangover (headache, nausea and difficulty concentrating) [13]. After this they were asked to rate on a scale of 1 to 10 their general feeling of wellbeing.

The subjects provided written consent and project was conducted according to the declaration of Helsinki.

After the project was completed the randomization code was broken and the data were analysed using Students paired t-test. The data were expressed as means and standard deviations. Potential treatment order or carry over effects were investigated using the methods of Hills and Armitage, 1979 [14]. Because the data were finite (0-100 or 0-10) and in one instance not continuous, they were also analysed using the nonparametric Wilcoxon Rank Sum test. The number of participants was chosen on the basis of a power calculation using an expected between day variability of the tests (from previous studies) of about $30 \%$. This indicated that with 19 subjects a difference between treatments of about $20 \%$ or more could be detected with $80 \%$ power and a two tailed alpha value of less than 0.05 . Differences less than $20 \%$ were not considered to be clinically significant.

\section{Results}

The population consisted of 10 male and 9 female volunteers aged 24 to 75 years (mean $38 \pm 7$ ). The mean alcohol intake during Rapid Recovery administration was $108 \pm 31 \mathrm{~g}$ (range 60-180 g) while the mean intake during dextrose administration was $104 \pm 35 \mathrm{~g}$ (range 84$204 \mathrm{~g})(\mathrm{P}=0.5368$-not significant).

The results of the visual analogue scales for the three common symptoms of hangover studied are presented in Table 1.

There were no treatment order or carry over effects and analysis of the data using the non-parametric test produced similar results. The very high level of statistical significance between the two treatments confirm that the study was adequately powered and that the treatment effects were large (Figure 1).

\section{Discussion}

The results of this study demonstrate that Rapid Recovery administered in the recommended manner is an effective preventative measure for the alleviation of at least some of the more prominent symptoms of hangover. This supports the impression gained from its' clinical use. It is not possible from our results to determine which components were responsible for this effect, although we believe that the contributions made by l-cysteine and ascorbic acid, both of which have a major effect on improving survival in rats poisoned with
Table 1. Results of the severity of symptoms of hangover (mean $\pm \mathrm{sd}$ ) and the percentage differences between dextrose and Rapid Recovery administration from visual analogue scales with 100 being the worst.

\begin{tabular}{|c|c|c|c|c|}
\hline Symptom & $\begin{array}{c}\text { Dextrose } \\
(\mathbf{0 - 1 0 0} \mathbf{~ m m})\end{array}$ & $\begin{array}{c}\text { Rapid Recovery } \\
\mathbf{( 0 - 1 0 0} \mathbf{~ m m})\end{array}$ & $\begin{array}{c}\text { \% change } \\
\text { between study } \\
\text { days }\end{array}$ & P value \\
\hline Nausea & $36 \pm 31$ & $10 \pm 12$ & $260 \%$ & 0.0035 \\
\hline Headache & $58 \pm 29$ & $18 \pm 17$ & $222 \%$ & 0.0003 \\
\hline $\begin{array}{c}\text { Poor } \\
\text { concentration }\end{array}$ & $50 \pm 29$ & $21 \pm 19$ & $138 \%$ & $<0.0001$ \\
\hline
\end{tabular}

\section{Feeling of wellbeing $n=19$ $P<0.00001$}

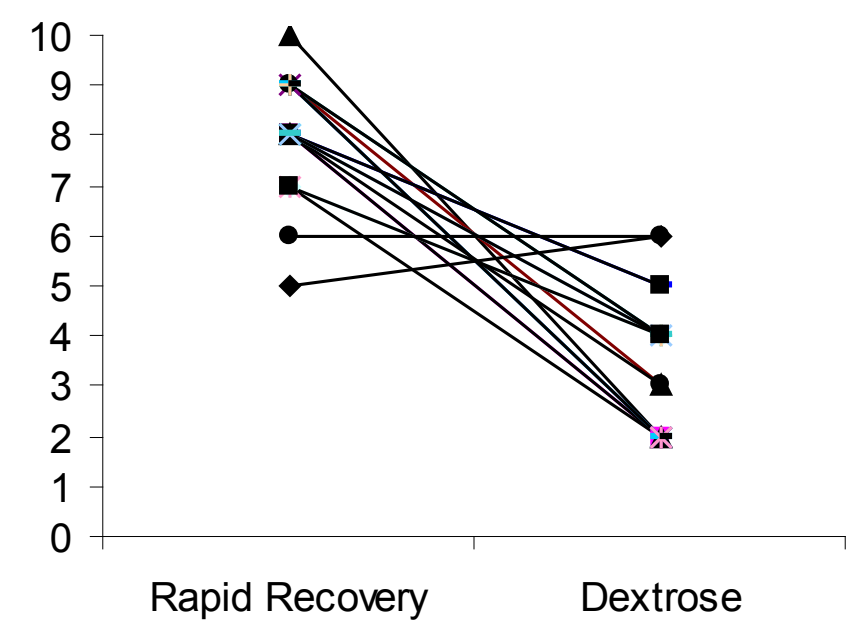

Figure 1. The reported degree of wellbeing on a scale of 0 (terrible) to 10 (excellent) on the two study days was $8.00 \pm 0.84$ for Rapid Recovery compared to $3.47 \pm 1.18$ for dextrose (means $\pm \mathrm{sd})(\mathrm{P}<0.00001)$.

acetaldehyde [7,9] are likely to be the most important. While the results of this study may support the acetaldehyde hypothesis of hangover pathogenesis [5], they by no means prove it. Rapid Recovery possesses potent anti oxidant effects that could neutralize oxygen free radicals. The generation of free radicals during alcohol metabolism and their subsequent toxic effect has been proposed as a mechanism involved in the pathogenesis of hangover [15].

Rapid Recovery is one of only a few compounds for which there are data from human studies to support claims of a reduction in hangover severity. These include Red Ginseng [16] and Korean Pear juice [17]. Red Ginseng and Korean Pear Juice appear to act by reducing alcohol levels and therefore must be taken at the commencement of alcohol consumption $[16,17]$. They appear to have more modest effects on the major hangover symptoms such as nausea and headache than Rapid Recovery. It should be noted that some of the currently marketed hangover remedies claim that the active component of their product is Pueraria lobata (Kudzu root). Pueraria lobata actually increases tissue acetaldehyde levels [18].

The results of the present evaluation indicate that Rapid Recovery, taken at the dose and in the schedule that is recommended, is an effective treatment for the reduction of at least some of the more disabling symptoms of alcohol-induced hangover. These findings may be of importance in adopting a harm minimization approach to alleviating the loss of productivity due to alcohol abuse. 


\section{Acknowledgements} people:

The authors wish to acknowledge the contributions of the following

Cassandra Dean-Rankin and Ashleigh Howes for assistance in conducting the project, Marlene Iffland for performing the randomization tasks and Diane Tran and Lauren Howes for assistance during the writing of the manuscript.

\section{Disclosures}

Rapid Recovery is wholly owned by Phoenix Pharmaceuticals Australia Pty. Ltd. Dr. J.B. Quinton is the Director and major shareholder of Phoenix Pharmaceuticals Australia Pty. Ltd. Professor L.G. Howes is a shareholder in this company and acts in an honorary medical director. R.M. Kemm has no disclosures.

\section{References}

1. Roche A, Pidd K, Kostadinov V (2016) Alcohol- and drug-related absenteeism: a costly problem. Aust N Z J Public Health 40: 236-238. [Crossref]

2. Bouchery EE, Harwood HJ, Sacks JJ, Simon CJ, Brewer RD (2006) Economic costs of excessive alcohol consumption in the U.S. 2006. Am J Prev Med 41: 516-24.

3. Pittler MH, Verster JC, Ernst E (2005) Interventions for preventing or treating alcohol hangover: systematic review of randomized controlled trials. Brit Med J 331: 1515-7.

4. Verster JC, Penning R (2010) Treatment and prevention of alcohol hangover. Curr Drug Abuse Rev 3: 103-109. [Crossref]

5. Eriksson CJ (2001) The role of acetaldehyde in the actions of alcohol (update 2000). Alcohol Clin Exp Res 25: 15S-32S. [Crossref]

6. Olson RE (1968) Nutrition and Alcoholism in: Modern Nutrition in Health and Disease (1968) Ross AC, Caballero B, Cousins RJ (Eds). Shils pp: 767-781.
7. Sprince H, Parker CM, Smith GG, Gonzales LJ (1974) Protection against acetaldehyde toxicity in the rat by L-cysteine, thiamine, and L-2-methylthiazolidine-4-carboxylic acid. Inflam Res 4: 125-30.

8. Cysteine. Over view. University of Maryland Medical Centre.

9. Sprince H, Parker CM, Smith GG, Gonzales LJ (1975) Protective action of ascorbic acid and sulfur compounds against acetaldehyde toxicity: implications in alcoholism and smoking. Agents Actions 5: 164-173.

10. Ginter E, Zloch Z, Ondreicka R (1998) Influence of vitamin C status on ethanol metabolism in guinea-pigs. Physiol Res 47: 137-141. [Crossref]

11. www.mayoclinic.org/drugs-supplements/vitamin-b6/dosing/hrb-20058788

12. Ylikahri RH, Leino T, Huttunen MO, Poso AR, Eriksson CJ et al. (1976) Effects of fructose and glucose on ethanol-induced metabolic changes and on the intensity of alcohol intoxication and hangover. J Clin Invest 6: 93-102.

13. Robertson BM, Piasecki TM, Slutske WS, Wood PK, Sher KJ, et al. (2012) Validity of the hangover symptoms scale: evidence from an electronic diary study. Alcohol Clin Exp Res 36: 171-177.

14. Hills M, Armitage P (1979) The two-period cross-over clinical trial. Br J Clin Pharmacol 8: 7-20. [Crossref]

15. Karadayian AG, Bustemante J Czerniczyniec A, Lombardi P, Cutrera RA, et al. (2015) Alcohol hangover induces mitochondrial dysfunction and free radical production in mouse cerebellum. Neuroscience 304: 47-59.

16. Lee MH, Kwak JH, Jeon G, Seo JH, Lee HS, et al. (2014) Red Ginseng relieves the effects of alcohol consumption and hangover symptoms in healthy men: a randomised crossover study. Food Funct 5: 528-534.

17. Lee H, Isse T, Kawamoto T, Baik HW, Park JY, Yang M (2013) Effect of Korean Pear (Pyruspyrifolia cv. Shingo) juice on hangover severity following alcohol consumption. Food Chem Toxicol 58: 101-106.

18. McGregor NR (2007) Pueraria lobata (Kudzu root) hangover remedies and acetaldehyde-associated neoplasm risk. Alcohol 41: 469-478.

Copyright: $\odot 2018$ Quinton JB. This is an open-access article distributed under the terms of the Creative Commons Attribution License, which permits unrestricted use, distribution, and reproduction in any medium, provided the original author and source are credited. 